\title{
Blood pressure after PREeclampsia/HELLP by SELF monitoring (BP-PRESELF): rationale and design of a multicenter randomized controlled trial
}

Hella E. C. Muijsers ${ }^{1 *}$ (D), Olivier W. H. van der Heijden², Karin de Boer ${ }^{3}$, Chantal van Bijsterveldt ${ }^{4}$, Ciska Buijs $5^{5}$, Jens Pagels ${ }^{6}$, Peter Tönnies ${ }^{7}$, Susanne Heiden ${ }^{8}$, Nel Roeleveld ${ }^{9}$ and Angela H. E. M. Maas ${ }^{1}$

\begin{abstract}
Background: Hypertensive disorders of pregnancy (HDP), such as preeclampsia (PE) or the Hemolysis Elevated Liver enzymes and Low Platelets (HELLP) syndrome are associated with elevated cardiovascular disease (CVD) risks, but standardized prevention guidelines after such pregnancies are lacking. Hypertension is the first emerging risk factor after PE/HELLP pregnancies and is a major risk factor for CVD. Hypertension before the age of 55 years may lead to various manifestations of end-organ damage at relatively young age. Therefore, timely treatment of elevated blood pressure is mandatory, but many of these high-risk women have long-term undetected and untreated hypertension before adequate treatment is initiated.
\end{abstract}

Aim: The aim of our study is to assess whether home blood pressure monitoring (HBPM) in women with a previous PE/HELLP pregnancy is a valuable tool for the early detection of hypertension.

Methods: Women with a history of both early and late PE/HELLP syndrome aged 40-60 years are invited to participate. Patients with a history of CVD, known hypertension and/or use of antihypertensive medication are excluded. Women are randomized between HPBM or 'usual care'. The primary outcome is feasibility and usability of HBPM after 1 year of follow-up.

Secondary outcomes will be the effectiveness of HPBM to detect hypertension, the efficacy of BP treatment, quality of life, health-related symptoms, work ability, and life-style behaviour.

The results of this study will provide better strategies for timely detection and prevention of hypertension in women after PE/HELLP.

Trial registration: ClinicalTrials.gov, NCT03228082. Registered June 15, 2017.

Keywords: Cardiovascular disease, eHealth, Preeclampsia, Hypertension, Home blood pressure monitoring, Cardiovascular risk factor

\footnotetext{
* Correspondence: Hella.Muijsers@radboudumc.nl

${ }^{1}$ Department of Cardiology, Radboud university medical center,

Geert-Grooteplein Zuid 10, 6525, GA, Nijmegen, The Netherlands

Full list of author information is available at the end of the article
}

(c) The Author(s). 2020 Open Access This article is distributed under the terms of the Creative Commons Attribution 4.0 International License (http://creativecommons.org/licenses/by/4.0/), which permits unrestricted use, distribution, and reproduction in any medium, provided you give appropriate credit to the original author(s) and the source, provide a link to the Creative Commons license, and indicate if changes were made. The Creative Commons Public Domain Dedication waiver (http://creativecommons.org/publicdomain/zero/1.0/) applies to the data made available in this article, unless otherwise stated. 


\section{Background}

Cardiovascular disease (CVD) is the leading cause of mortality in women worldwide. One of the major risk factors is high blood pressure [1]. In women, 38\% of cardiovascular mortality could be prevented if this risk factor could be eliminated [2]. Important female-specific risk factors for CVD are hypertensive disorders of pregnancy (HDP), which may induce earlier occurrence of high blood pressure [3].

HDP complicate $10-15 \%$ of all pregnancies [4, 5]. This group consists of chronic hypertension, gestational or pregnancy-induced hypertension $(\mathrm{PIH})$, preeclampsia (PE) and Hemolysis Elevated Liver enzymes Low Platelets (HELLP) syndrome. De novo hypertension during pregnancy is diagnosed when hypertension is present after 20 weeks of gestation.

PE and HELLP syndrome represent the most severe HDP with the highest CVD risk and complicate $3-5 \%$ of all pregnancies [6-8]. PE is diagnosed when gestational hypertension is complicated by proteinuria, maternal organ dysfunction and/or fetal growth restriction [9]. HELLP syndrome causes severe maternal metabolic, vascular, and thrombotic complications. Although maternal mortality in the Netherlands is low, PE/HELLP remains the number one cause [10].

Many women with a history of PE/HELLP remain undiagnosed for their hypertension, since female-specific risk factors are not routinely accounted for in the SCORE or other cardiovascular risk charts. These young women leading busy lives are not likely to seek medical attention to check their blood pressure regularly, and they do not want to be considered as 'patients' lifelong either. Therefore, elevated blood pressure may remain undetected and untreated for many years. These considerations can be surpassed using self-monitoring applications.

The aim of our study is to assess whether home blood pressure monitoring (HBPM) in women with a previous history of PE/HELLP is a valuable tool in clinical practice for early detection and timely treatment of hypertension.

\section{Premature endothelial dysfunction after PE/HELLP}

The etiology of PE is still largely unknown. It is hypothesized that PE/HELLP is a result of poor placentation causing a widespread inflammatory response resulting in generalized endothelial dysfunction in the placental and maternal circulation $[11,12]$. A balanced immune response is necessary in normal pregnancy for adequate placentation, but the immune response is exaggerated in PE/HELLP. This overreactive inflammatory response is characterized by an increase in pro-inflammatory $\mathrm{T}$ lymphocytes and a decrease in regulatory $\mathrm{T}$ cells, leading to elevated pro-inflammatory factors, such as cytokines, leukocytes, and adhesion molecules $[13,14]$. This results in endothelial dysfunction in the placenta and maternal circulation. It is hypothesized that PE may be the result of a preexistent elevated CVD risk in the mother [15, 16].

Evidence is increasing that maternal endothelial dysfunction persists after such a complicated pregnancy, increasing the risk of hypertension and end-organ damage at young age $[17,18]$. Furthermore, there is compelling evidence that an enhanced inflammatory system is a major contributor to atherosclerosis and cardiovascular disease [19-21]. Both PE/HELLP and the development of atherosclerotic disease share several common pathophysiological pathways.

\section{Hypertension after PE/HELLP syndrome}

In the last two decades, a large body of evidence has shown that women after PE/HELLP are at increased risk to develop hypertension before the age of 55 years. In a meta-analysis by Bellamy et al., a relative risk of 3.70 (95\% confidence interval (CI) 2.70-5.05) was found for hypertension after PE [22]. We showed previously that $43 \%$ of women after early PE had hypertension before the age of 40 years, compared to $17 \%$ in a control group of women after a normotensive pregnancy [23]. Behrens et al. demonstrated that women with HDP had a 30\% risk of post-pregnancy hypertension, especially in the first 1-2 years [24]. Several international guidelines have now recognized HDP as an important CVD risk factor and recommend screening and management of emerging risk factors in affected women $[5,25]$. The excess CVD risk after HDP might be associated with traditional modifiable cardiovascular risk factors, such as elevated blood pressure [26]. However, it remains to be established how, when, and by whom the blood pressure of these young women should be monitored optimally.

\section{eHealth /home blood pressure monitoring}

Up to half of an individual's CVD risk is attributable to high blood pressure, which makes timely diagnosis of hypertension very important [27]. In the latest 2018 European Society of Cardiology/European Society of Hypertension (ESC/ESH) guideline for the management of arterial hypertension [28] and the 2017 American College of Cardiology/American Hypertension Association (ACC/AHA) guideline on high blood pressure [29], thresholds for diagnosis and treatment of hypertension have shifted towards lower normal blood pressure values. There are various ways to check blood pressure, e.g. in-office BP measurement, home blood pressure monitoring (HBPM), and 24-h ambulatory blood pressure monitoring (ABPM). Nowadays, HBPM is complementary to in-office blood pressure measurements and ABPM in the diagnosis and treatment of hypertension.

HBPM is a simple way to check an individual's usual blood pressure and has better reproducibility than ABPM 
[30]. Several advantages of HBPM are that it is easy to use and easy to learn and it is not necessary to visit a general practitioner or hospital, which makes it accessible and relatively inexpensive [31]. HBPM can also distinguish between white coat hypertension and masked hypertension. In a systematic review by Stergiou et al. HBPM was assessed as being as reliable as ABPM in the diagnosis of hypertension [32]. This fits nicely into the current era of modern eHealth applications and personalized medicine with the patient-as-partner in treatment [33]. Another advantage of more intense patient involvement is the higher motivation for lifestyle adherence and better intake of prescribed medication [34]. Since women with a history of PE/HELLP have a life-time elevated CVD risk, selfassessment of blood pressure provides a window of opportunity for timely preventive measures.

Using HBPM, hypertension is diagnosed if the average blood pressure of twice-daily measurements for at least 3, but preferably 7 , days is $\geq 135 / 85 \mathrm{mmHg}[28,29,31]$. It has not been established yet, however, whether selfmeasurement of blood pressure may be more effective and feasible for prospective follow-up of women with an elevated CVD risk due to previous PE/HELLP, than incidental blood pressure measurements at a physician's office. We hypothesize that HBPM will identify women with elevated blood pressure more timely than usual care.

\section{Methods}

\section{Study design and participants}

The feasibility and usability of HBPM to detect hypertension will be evaluated in a multicenter randomized controlled trial (RCT). Participants are women aged 40 to 60 years with a history of PE/HELLP. Seven departments of Obstetrics in the Euregio Rijn-Waal, in The Netherlands and Germany, participate as recruiting centers. All study visits will be executed at the department of Cardiology at the Radboudumc, the principal study center. The databases of the seven departments of Obstetrics were searched for patients with $\mathrm{PE}$ and/or HELLP in their medical history. Previous PE/HELLP was defined as diastolic blood pressure (BP) $\geq 90 \mathrm{mmHg}$ and/ or systolic $\mathrm{BP} \geq 140 \mathrm{mmHg}$ and proteinuria $\geq 300 \mathrm{mg} / 24$ $h$, more than 1 year ago. Both patients with early-onset PE (i.e. delivery before 34 weeks of gestation) and lateonset PE (i.e. delivery from 34 weeks of gestation onwards) will be included, as well as patients after eclampsia or HELLP syndrome. Exclusion criteria are previous cardiovascular events (such as myocardial infarction, stroke, documented ischemic heart disease), already diagnosed hypertension and/or use of antihypertensive medication, not having a smartphone, or inability to perform self-measurement of blood pressure. Pregnant women or women aiming to have another pregnancy will be excluded. All eligible patients are invited to participate by letter. In case no response is received after two weeks, we will call the patient to ask for participation. The participating women are randomized to HBPM (intervention group) or 'usual care' (control group) using the randomization method in Castor EDC [35]. Patients in the usual care group will not receive planned blood pressure measurements, but they will be asked to register their blood pressure if a measurement is done at a doctor's visit.

\section{Data collection}

At the baseline visit, the randomization and a physical examination will be conducted consisting of measurements of blood pressure, heart rate, weight, height, and waist and hip circumference. Standardized blood pressure measurements will be performed on both arms, with at least 3 different readings. Waist and hip circumference will be measured with a non-stretchable tape measure over light clothing: waist circumference at the narrowest point of the abdomen and hip circumference at the widest diameter around the buttocks. Finally, a non-fasting blood sample $(13 \mathrm{~mL})$ will be drawn. The blood samples will be centrifuged at $1500 \mathrm{G}$ for $15 \mathrm{~min}$ within $4 \mathrm{~h}$, separated into equal volumes $(250 \mu \mathrm{L})$, and frozen immediately at minus $80^{\circ} \mathrm{C}$. These samples will be stored for future biomarker analysis.

All participants will also be asked to complete structured online questionnaires at several occasions during follow-up. At baseline, information will be obtained on personal medical history, family history of CVD, obstetric history, cardiovascular symptoms, menopausal symptoms, and lifestyle (e.g. physical activity, dietary patterns, and smoking). In addition, several standardized questionnaires will be administered, such as the 36-item Short Form Health Survey (SF-36), the Copenhagen Psychosocial Questionnaire (COPSOQ-II) on working ability [36], and questionnaires on need for recovery [37] and work-related recovery opportunities [38]. During follow-up, all participants will be asked to complete an online questionnaire on psychosocial well-being (SF-12) every month. The intervention group will also be asked to complete a questionnaire on feasibility and usability of the blood pressure device after 6 months and 1 year of follow-up. At the final visit after 1 year, all baseline measurements and questionnaires will be repeated in both groups.

\section{Home blood pressure monitoring (HBPM)}

HBPM will be performed using the Withings BPM device. This device was validated for home blood pressure measurements according to the ESH International Protocol [39]. The Withings BPM device is a wireless blood pressure monitor, which connects to an application on the woman's smartphone using Bluetooth. Measurements uploaded to the application will automatically be entered 
into an online patient health file (Patients Know Best ${ }^{\circ}$ ), which is accessible for the study coordinators to check the blood pressure levels regularly. The participants will be instructed to perform the blood pressure measurements according to the ESH guideline [31] for blood pressure home monitoring. These guidelines advise BP measurements in the morning and in the evening, at least two measurements per occasion, preferably over 7 consecutive days. Currently, HBPM is only used for self-management in poorly controlled hypertension [40-44], but not yet to detect hypertension in high-risk patients. As a result, the guidelines do not describe the frequency of the measurement periods. For this study, the participants will be asked to install a 7-days measurement period every month during 1 year.

\section{Outcomes}

The primary outcome is the feasibility and usability of HBPM during 1 year of follow-up. The participants in the intervention group will receive monthly feedback on their blood pressure measurements. In case of elevated blood pressure, participants will be advised to contact their general practitioner for treatment advice. Feasibility and usability as well as protocol adherence and persistence to HBPM will be determined using the questionnaires completed after 6 months and 1 year of follow-up and the actual BP measurements. Protocol adherence is the proportion of participants in the intervention group who self-monitor their blood pressure twice daily for at least 4 consecutive days every month during 1 year of follow-up. Persistence to HBPM is defined as the proportion of participants in the intervention group who measure their blood pressure until the final follow-up visit. The secondary outcomes include blood pressure levels and the prevalence of hypertension in the intervention group compared to the control group at 1 year of follow-up. In addition, quality of life, work capability, and cardiac and/or hypertensive symptoms will be compared between the groups.

\section{Sample size calculation}

Formally, a sample size calculation is not required for a feasibility study. The prevalence of PE/HELLP in the Dutch/German population is $3-5 \%$ of all pregnancies per year. Among 5.5 million inhabitants in the study region as a whole, we expect approximately 55,000 pregnancies each year, among which an estimated 2200 are complicated by PE/HELLP. If the participating obstetric centers (out of 28 hospitals in the region) cover approximately $20 \%$ of these pregnancies, more than 4000 women with PE/HELLP should have been seen in the past 10 years. These women can be considered our study base from which the study participants can be recruited.

Within the time-frame and the financial constraints of the study, it would be realistic to recruit approximately
200 eligible women, with inclusion of 100 women in the intervention group and 100 women in the usual care group. For the secondary endpoint BP, we would be able to find differences of approximately 5 or more $\mathrm{mmHg}$ in SBP (assuming a SD of $12 \mathrm{mmHg}$ ) and 4 or more $\mathrm{mmHg}$ in DBP (with a SD of $9 \mathrm{mmHg}$ ) with $80 \%$ power and a 0.05 level of significance (two-sided), assuming less than $10 \%$ loss-to-follow-up. In comparison to other selfmonitoring of blood pressure studies, a difference of 5 $\mathrm{mmHg}$ in systolic blood pressure is plausible [45].

\section{Statistical analysis}

Data analysis will be performed using SPSS (IBM). The characteristics of the participants will be described using means with $95 \%$ confidence intervals for normally distributed continuous variables or medians plus ranges otherwise, and proportions for categorical variables. Both qualitative and quantitative analyses will be performed on the primary and secondary outcomes with a range of statistical techniques to compare the baseline data with the 6 months and 1 year follow-up data taking into account study group. To describe protocol adherence and persistence to HBPM, survival analyses will be performed.

\section{Ethical considerations}

This study was approved by the Regional Committee on Research involving Human Subjects ArnhemNijmegen (number 2016-3006). This trial was registered in the Clinical Trials Register, NCT03228082, https://clinicaltrials.gov/ct2/show/NCT03228082, date of registration: June 15, 2017.

\section{Discussion}

We aim to demonstrate that HBPM is an acceptable and easy way to check blood pressure regularly. We assume that by using HBPM, the blood pressure in de intervention group will be regulated better after 1 year of follow-up compared to the control group. By including the patient actively in HBPM, we expect to be able to diagnose hypertension earlier and to establish more timely treatment. If HBPM shows to be a feasible method to diagnose hypertension in the high-risk women included in this study, this method may be useful for follow-up starting directly after pregnancies complicated by hypertensive disorders. The incidence of hypertension among women with these pregnancy complications is expected to be even higher than the findings of this study will show, since we exclude women with already diagnosed hypertension. A limitation is that we cannot confirm the diagnosis hypertension using ABPM for all women in the study. However, recent studies showed a diagnostic agreement ranging from 80 to 90\% between the two methods [46]. Therefore, we expect that HBPM is a valuable tool for blood pressure monitoring for long-term follow-up. 


\section{Abbreviations}

ABPM: Ambulatory blood pressure monitoring; ACC: American College of Cardiology; AHA: American Hypertension Association; BP: Blood pressure; Cl: Confidence interval; COPSOQ-II: Copenhagen Psychosocial Questionnaire; CVD: Cardiovascular disease; ESC: European Society of Cardiology; ESH: European Society of Hypertension; HBPM: Home blood pressure monitoring; HDP: Hypertensive disorders of pregnancy; HELLP: Hemolysis, elevated liver enzymes, low platelets; PE: Preeclampsia; PIH: Pregnancyinduced hypertension; RCT: Randomized-controlled trial; RR: Relative risk; SF12: 12-item Short Form Health Survey; SF-36: 36-item Short Form Health Survey

\section{Acknowledgements}

ReshapeHealth.

\section{Authors' contributions}

$H M, O v d H, K d B, C v B, C B, J P, P T, S H, N R$ and AM were involved in the conception and design of the work. HM, OvdH, NR and AM drafted the manuscript. All authors mentioned in the manuscript are member of the BPPRESELF study group. All authors (HM, OvdH, KdB, CvB, CB, JP, PT, SH, NR and AM) edited the manuscript and read and approved the final manuscript.

\section{Funding}

The Blood Pressure after PREeclampsia/HELLP by SELF-monitoring (BP-PRESELF) study will be performed in patients living in the Euregio Rijn-Waal and is part of the INTERREG-V-A program Germany-The Netherlands "Zorg Verbindt" (203072/WP3) and co-financed by the European Union (EU), Ministry for Economy, Innovation, Digitalization and Energy of the Federal State of Nordrhein-Westfalen (Germany) and the Province of Gelderland (The Netherlands). The funding body had no role in study design and is neither involved in collection, analysis and interpretation of data nor in writing the manuscript.

\section{Availability of data and materials}

Not applicable.

\section{Ethics approval and consent to participate}

This study was approved by the Regional Committee on Research involving Human Subjects Arnhem-Nijmegen (number 2016-3006). All participants will provide written informed consent before inclusion in this study.

\section{Consent for publication}

Not applicable.

\section{Competing interests}

The authors declare that they have no competing interests.

\section{Author details}

'Department of Cardiology, Radboud university medical center, Geert-Grooteplein Zuid 10, 6525, GA, Nijmegen, The Netherlands. ${ }^{2}$ Department of Obstetrics and Gynecology, Radboud university medical center, Geert-Grooteplein Zuid 10, 6525, GA, Nijmegen, The Netherlands. ${ }^{3}$ Department of Obstetrics and Gynecology, Rijnstate, Wagnerlaan 55, 6815, $A D$, Arnhem, The Netherlands. ${ }^{4}$ Department of Obstetrics and Gynecology, Canisius-Wilhelmina Hospital, Weg door Jonkerbos 100, 6532, SZ, Nijmegen, The Netherlands. ${ }^{5}$ Department of Obstetrics and Gynecology, Maasziekenhuis Pantein, Dokter Kopstraat 1, 5835 BV, Beugen, The Netherlands. ${ }^{6}$ Department of Obstetrics and Gynecology, St. Josef Hospital Moers, Asberger Strasse 4, 47441 Moers, Germany. ${ }^{7}$ Department of Obstetrics and Gynecology, Bethanien Hospital Moers, Bethanienstrasse 21, 47441 Moers, Germany ${ }^{8}$ Department of Obstetrics and Gynecology, St. Antonius Hospital Kleve, Albersallee 5-7, 47533 Kleve, Germany. ${ }^{9}$ Department for Health Evidence, Radboud Institute for Health Sciences, Radboud university medical center, Geert-Grooteplein Zuid 10, 6525, GA, Nijmegen, The Netherlands.

Received: 1 February 2019 Accepted: 20 February 2020 Published online: 04 March 2020

\section{References}

1. Lim SS, Vos T, Flaxman AD, Danaei G, Shibuya K, Adair-Rohani H, et al. A comparative risk assessment of burden of disease and injury attributable to
67 risk factors and risk factor clusters in 21 regions, 1990-2010: a systematic analysis for the global burden of disease study 2010. Lancet. 2012;380(9859): 2224-60.

2. Patel SA, Winkel M, Ali MK, Narayan KM, Mehta NK. Cardiovascular mortality associated with 5 leading risk factors: national and state preventable fractions estimated from survey data. Ann Intern Med. 2015;163(4):245-53.

3. Heida KY, Bots ML, de Groot CJ, van Dunne FM, Hammoud NM, Hoek A, et al. Cardiovascular risk management after reproductive and pregnancyrelated disorders: a Dutch multidisciplinary evidence-based guideline. Eur J Prev Cardiol. 2016;23(17):1863-79.

4. Stuart JJ, Tanz LJ, Cook NR, Spiegelman D, Missmer SA, Rimm EB, et al. Hypertensive disorders of pregnancy and 10-year cardiovascular risk prediction. J Am Coll Cardiol. 2018;72(11):1252-63.

5. Piepoli MF, Hoes AW, Agewall S, Albus C, Brotons C, Catapano AL, et al. 2016 European Guidelines on cardiovascular disease prevention in clinical practice: The Sixth Joint Task Force of the European Society of Cardiology and Other Societies on Cardiovascular Disease Prevention in Clinical Practice (constituted by representatives of 10 societies and by invited experts)Developed with the special contribution of the European Association for Cardiovascular Prevention \& Rehabilitation (EACPR). Eur Heart J. 2016;37(29):2315-81.

6. McDonald SD, Malinowski A, Zhou Q, Yusuf S, Devereaux PJ. Cardiovascular sequelae of preeclampsia/eclampsia: a systematic review and meta-analyses. Am Heart J. 2008;156(5):918-30.

7. Brown MC, Best KE, Pearce MS, Waugh J, Robson SC, Bell R. Cardiovascular disease risk in women with pre-eclampsia: systematic review and metaanalysis. Eur J Epidemiol. 2013;28(1):1-19.

8. Mannisto T, Mendola P, Vaarasmaki M, Jarvelin MR, Hartikainen AL, Pouta A, et al. Elevated blood pressure in pregnancy and subsequent chronic disease risk. Circulation. 2013:127(6):681-90.

9. Tranquilli AL, Dekker G, Magee L, Roberts J, Sibai BM, Steyn W, et al. The classification, diagnosis and management of the hypertensive disorders of pregnancy: a revised statement from the ISSHP. Pregnancy Hypertens. 2014; 4(2):97-104.

10. Schutte J, Steegers E, Schuitemaker N, Santema J, de Boer K, Pel M, et al. Rise in maternal mortality in the Netherlands. BJOG. 2010;117(4):399-406.

11. Steegers EAP, von Dadelszen P, Duvekot JJ, Pijnenborg R. Pre-eclampsia. Lancet. 2010;376(9741):631-44.

12. Redman CW, Sacks GP, Sargent IL. Preeclampsia: an excessive maternal inflammatory response to pregnancy. Am J Obstet Gynecol. 1999;180(2 Pt 1):499-506.

13. Harmon AC, Cornelius DC, Amaral LM, Faulkner JL, Cunningham MW Jr, Wallace $K$, et al. The role of inflammation in the pathology of preeclampsia. Clin Sci (Lond). 2016;130(6):409-19.

14. Redman CW, Sargent IL. Placental stress and pre-eclampsia: a revised view. Placenta. 2009;30(Suppl A):S38-42.

15. Kalafat E, Thilaganathan B. Cardiovascular origins of preeclampsia. Curr Opin Obstet Gynecol. 2017;29(6):383-9.

16. Perry H, Khalil A, Thilaganathan B. Preeclampsia and the cardiovascular system: an update. Trends Cardiovasc Med. 2018

17. Chambers JC, Fusi L, Malik IS, Haskard DO, De Swiet M, Kooner JS. Association of maternal endothelial dysfunction with preeclampsia. JAMA. 2001:285(12):1607-12.

18. Yinon Y, Kingdom JC, Odutayo A, Moineddin R, Drewlo S, Lai V, et al. Vascular dysfunction in women with a history of preeclampsia and intrauterine growth restriction: insights into future vascular risk. Circulation. 2010;122(18):1846-53.

19. Kvehaugen AS, Dechend R, Ramstad HB, Troisi R, Fugelseth D, Staff AC. Endothelial function and circulating biomarkers are disturbed in women and children after preeclampsia. Hypertension. 2011;58(1):63-9.

20. Libby P, Nahrendorf M, Swirski FK. Leukocytes link local and systemic inflammation in ischemic cardiovascular disease: an expanded "cardiovascular continuum". J Am Coll Cardiol. 2016;67(9):1091-103.

21. Staff AC, Johnsen GM, Dechend R, Redman CWG. Preeclampsia and uteroplacental acute atherosis: immune and inflammatory factors. J Reprod Immunol. 2014;101-102:120-6.

22. Bellamy L, Casas JP, Hingorani AD, Williams DJ. Pre-eclampsia and risk of cardiovascular disease and cancer in later life: systematic review and metaanalysis. BMJ. 2007;335(7627):974.

23. Drost JT, Arpaci G, Ottervanger JP, de Boer MJ, van Eyck J, van der Schouw $\mathrm{YT}$, et al. Cardiovascular risk factors in women 10 years post early 
preeclampsia: the preeclampsia risk EValuation in FEMales study (PREVFEM). Eur J Prev Cardiol. 2012;19(5):1138-44.

24. Behrens I, Basit S, Melbye M, Lykke JA, Wohlfahrt J, Bundgaard H, et al. Risk of post-pregnancy hypertension in women with a history of hypertensive disorders of pregnancy: nationwide cohort study. BMJ. 2017;358:3078.

25. Bushnell C, McCullough LD, Awad IA, Chireau MV, Fedder WN, Furie KL, et al. Guidelines for the prevention of stroke in women: a statement for healthcare professionals from the American Heart Association/American Stroke Association. Stroke. 2014;45(5):1545-88.

26. Haug EB, Horn J, Markovitz AR, Fraser A, Klykken B, Dalen H, et al. Association of Conventional Cardiovascular Risk Factors with Cardiovascular Disease after Hypertensive Disorders of pregnancy: analysis of the NordTrøndelag health study. JAMA Cardiol. 2019;4(7):628-35.

27. Lawes CMM, Hoorn SV, Rodgers A. Global burden of blood-pressure-related disease, 2001. Lancet. 2008;371(9623):1513-8.

28. Williams B, Mancia G, Spiering W, Agabiti Rosei E, Azizi M, Burnier M, et al. 2018 ESC/ESH guidelines for the management of arterial hypertension. Eur Heart J. 2018;39(33):3021-104.

29. Whelton PK, Carey RM, Aronow WS, Casey DE Jr, Collins KJ, Dennison Himmelfarb C, et al. 2017 ACC/AHA/AAPA/ABC/ACPM/AGS/APhA/ASH/ ASPC/NMA/PCNA guideline for the prevention, detection, Evaluation, and Management of High Blood Pressure in adults: a report of the American College of Cardiology/American Heart Association task force on clinical practice guidelines. Hypertension. 2018;71(6):e13-e115.

30. Warren RE, Marshall T, Padfield PL, Chrubasik S. Variability of office, 24-hour ambulatory, and self-monitored blood pressure measurements. Br J Gen Pract. 2010;60(578):675-80.

31. Parati G, Stergiou GS, Asmar R, Bilo G, de Leeuw P, Imai Y, et al. European Society of Hypertension practice guidelines for home blood pressure monitoring. J Hum Hypertens. 2010;24(12):779-85.

32. Stergiou GS, Bliziotis IA. Home blood pressure monitoring in the diagnosis and treatment of hypertension: a systematic review. Am J Hypertens. 2011; 24(2):123-34.

33. Richards T, Montori VM, Godlee F, Lapsley P, Paul D. Let the patient revolution begin. BMJ. 2013;346:f2614.

34. McManus RJ, Mant J, Franssen M, Nickless A, Schwartz C, Hodgkinson J, et al. Efficacy of self-monitored blood pressure, with or without telemonitoring, for titration of antihypertensive medication (TASMINH4): an unmasked randomised controlled trial. Lancet. 2018.

35. BVC. Castor Electronic Data Capture. Amsterdam 2016.

36. Pejtersen JH, Kristensen TS, Borg V, Bjorner JB. The second version of the Copenhagen Psychosocial Questionnaire. Scand J Public Health. 2010;38(3_ suppl):8-24.

37. van Veldhoven $\mathrm{M}$, Broersen $\mathrm{S}$. Measurement quality and validity of the "need for recovery scale". Occup Environ Med. 2003;60(Suppl 1):i3-9.

38. van Veldhoven MJ, Sluiter JK. Work-related recovery opportunities: testing scale properties and validity in relation to health. Int Arch Occup Environ Health. 2009;82(9):1065-75.

39. Topouchian J, Agnoletti D, Blacher J, Youssef A, Chahine MN, Ibanez I, et al. Validation of four devices: Omron M6 comfort, Omron HEM-7420, Withings BP-800, and Polygreen KP-7670 for home blood pressure measurement according to the European Society of Hypertension International Protocol. Vasc Health Risk Manag. 2014;10:33-44.

40. Margolis KL, Asche SE, Bergdall AR, Dehmer SP, Groen SE, Kadrmas HM, et al. Effect of home blood pressure telemonitoring and pharmacist management on blood pressure control: a cluster randomized clinical trial. JAMA. 2013;310(1):46-56.

41. Verberk WJ, Kroon AA, Lenders JW, Kessels AG, van Montfrans GA, Smit AJ, et al. Self-measurement of blood pressure at home reduces the need for antihypertensive drugs: a randomized, controlled trial. Hypertension. 2007; 50(6):1019-25

42. McManus RJ, Mant J, Bray EP, Holder R, Jones Ml, Greenfield S, et al. Telemonitoring and self-management in the control of hypertension (TASMINH2): a randomised controlled trial. Lancet. 2010;376(9736):163-72.

43. McManus RJ, Mant J, Haque MS, Bray EP, Bryan S, Greenfield SM, et al. Effect of self-monitoring and medication self-titration on systolic blood pressure in hypertensive patients at high risk of cardiovascular disease: the TASMIN-SR randomized clinical trial. JAMA. 2014;312(8):799-808.

44. Cairns AE, Tucker KL, Leeson P, Mackillop LH, Santos M, Velardo C, et al. SelfManagement of Postnatal Hypertension: the SNAP-HT trial. Hypertension. 2018;72(2):425-32.
45. McManus RJ, Bray EP, Mant J, Holder R, Greenfield S, Bryan S, et al. Protocol for a randomised controlled trial of telemonitoring and selfmanagement in the control of hypertension: telemonitoring and self-management in hypertension. [ISRCTN17585681]. BMC Cardiovasc Disord. 2009;9:6. https:// doi.org/10.1186/1471-2261-9-6.

46. Stergiou GS, Omboni S, Parati G. Home or ambulatory blood pressure monitoring for the diagnosis of hypertension? J Hypertens. 2015;33(8): $1528-30$.

\section{Publisher's Note}

Springer Nature remains neutral with regard to jurisdictional claims in published maps and institutional affiliations.
Ready to submit your research? Choose BMC and benefit from:

- fast, convenient online submission

- thorough peer review by experienced researchers in your field

- rapid publication on acceptance

- support for research data, including large and complex data types

- gold Open Access which fosters wider collaboration and increased citations

- maximum visibility for your research: over $100 \mathrm{M}$ website views per year

At BMC, research is always in progress.

Learn more biomedcentral.com/submissions 